Abstract\#: A-2021-RE10013

Tao Xingzhi Study Association of China \& Huzhou University

May 28-30, 2021, Huzhou, Zhejiang Province, China

\title{
Research on Construction and Implementation of Kindergarten Vitality Curriculum
}

\section{Qun Xu, Xiaofang Yao}

Affiliation: Jincheng Center Kindergarten, Hangzhou 310000, Zhejiang, China Address: Jincheng Center Kindergarten, Hangzhou 310000, Zhejiang, China

Correspondence to: Qun Xu, E-mail: 542792975@qq.com

DOI: https://doi.org/10.15354/sief.21.s1.ab040

The authors declare no competing interest.

The research is based on the construction concept of "teaching with life, teaching for life" and was designed from "clearing curriculum goals" and "constructing curriculum content". Also, it focuses on improving the implementation level of teachers' courses in the theme review, enhancing the children's vitality in project forwarding, and promoting children's viability at play, which realized the practical vitality enhancement of children. As a result, children will be fond of learning, knowing how to play, becoming more self-independent, and more active participating. The teachers' professional development has been highlighted, which manifested in the transformation of teaching curriculum perspective and the achievement; the initial scale of curriculum construction preliminary expressed the environment and system of life education.

Keywords

Vitality Curriculum, Curriculum Structure, Curriculum Implementation

Science Insights Education Frontiers, 2021 September 13; Vol. 10, Suppl. 1, pp.10. 